\title{
INSTRUCTIONAL DESIGN AND STUDENT LEARNING IN PROFESSIONAL LEGAL EDUCATION
}

\author{
JULIE MACFARLANE* \& PAT BOYLE**
}

\section{INTRODUCTION}

The study which is described in this paper was designed with two complementary objectives in mind. The first objective was to carry out research to discover more about student conceptions of their learning in an educational program which would introduce a new approach to learning and challenge their expectations. The researchers - an instructional evaluation specialist and a law teacher - were particularly concerned in the first stage to explore as wide a range of student conceptions and reactions to the learning process as possible and then to attempt to draw some general observations from those results. A phenomenographic ${ }^{1}$ approach was used to leave open the possibility of discovering unintended and unexpected outcomes. The phenomenographic approach focuses on "mapping the qualitatively different ways in which people experience, conceptualise, perceive and understand various aspects of and phenomena in the world around them."2 To this end, the researchers sought from student respondents as wide a range as possible of personal responses and reactions to their learning experiences and environment.

The second objective of the study was to consider the question whether or not the design principles of the new program achieved their intended outcomes. These design principles and their anticipated implications for student learning described in detail below. The second objective of the project was therefore to provide 
information for decision-makers ${ }^{3}$ with which to evaluate the success of the new program in achieving its stated goals (including intended processes) and on which to ground program revisions and modifications for the second year of operation. These two drivers for the study provided a dual motivation to explore the impact of this new program on a sample of its first year student entrants. In order to ensure that the research results from the project could be meaningful and usefully translated into evaluative judgements about the success of the program in meeting its goals, three working hypotheses were formulated which were used to guide the data-gathering phase of the project; that is, face-to-face interviews conducted with the students. The three working hypotheses were derived from the design principles of the new program and knowledge of the students' previous educational experiences and approaches to learning. The design principles of the program and the working hypotheses themselves are discussed in detail below.

The empirical stage of the study took the form of a set of oneon-one interviews with a sample group of students from the new program, just three months into the program. The methodology used for these interviews, the working hypotheses which guided them and an analysis of the data derived follow below.

\section{CONTEXT AND BACKGROUND}

The Postgraduate Certificate in Laws (the PCLL) is the professional training course which Bachelor of Laws (LLB) graduates are required to complete before they can enter the practical apprenticeship stage of their professional training in Hong Kong, either in articles with a firm of solicitors or as a barrister's pupil. It is a one year full-time program and is currently offered by Hong Kong University and, since October 1991, the City Polytechnic of Hong Kong. The PCLL is therefore the approximate equivalent qualification in Hong Kong to the Law Society Finals or Bar Finals in England and Wales; the Bar Admissions Courses in the United States and Canada; and the Practical Training Courses which operate in many Australian states.

The development of the new PCLL at City Polytechnic was regarded by the original course design team as a unique opportunity to create the best possible program of postgraduate professional legal education using the most successful ideas pioneered on 
professional programs throughout the common law world. In Hong Kong the common law system continues in place until 1997 and theoretically beyond. ${ }^{4}$ The program attempts to reconcile what we know about the conditions and special needs of legal practice in Hong Kong with the lessons of experience on optimising the conditions and the outcomes of learning for trainee lawyers in other parts of the world. None of the fundamental educational principles underpinning the program's development nor the methods of teaching and learning is new or untested. What is new is the particular combination of ideas and methods which took shape in the first year of the program's delivery, 1991-92.

\section{DESIGNING THE PCLL: FIRST PRINCIPLES}

We assumed that most students entering the program would be accustomed to learning in a traditional didactic setting with the teacher perceived as the authority figure with the desired "knowledge" which could be transmitted and then learned by the student. Traditionally administered tests emphasising objective conceptions of knowledge underlined this mode of learning as essentially passive and highly teacher directed. This assumption was based on both what we had come to expect from law school entrants in the West and from what we knew about the educational model and systems of learning in Hong Kong.

In designing the new PCLL a conscious decision was taken to challenge this traditional model of learning and the established hegemony of legal education. This decision reflected a number of international trends in professional legal education, including the recognition by government commissions of inquiry that the products of traditional didactic legal education are not meeting the professions expectations nor equipping graduates effectively for legal practice; ${ }^{5}$ and a developing body of research which highlights the importance of personal development during professional education, in order to build mature career professionals who have personal criteria for decision-making and a sense of self-confidence when faced with less than standard situations in practice, ${ }^{6}$ and who can act as effective problem-solvers. ${ }^{7}$

The instructional design of a professional program in law should therefore encourage the development of individual problemsolving skills as well as increase substantive knowledge of the law. 
For example, if graduates were equipped with effective research skills they would be better prepared to face legal practice where their current legal knowledge would inevitably prove either inadequate for all situations they might encounter or rapidly out-ofdate. ${ }^{8}$

In the development of the PCLL program the first step was to identify a number of operational principles which would determine the overall direction of the course and serve as a point of reference for all future decisions on teaching/ learning strategy, assessment methods, course content, class size, learning environment and so on. ${ }^{9}$ These were deliberately considered and described before drawing up a detailed statement of course objectives. ${ }^{10}$ The operational principles for the PCLL represent key beliefs about maximising the effectiveness of professional education shared by the course team and function effectively as an educational "Credo" for the program. They include the following:

a there is no one model of effective legal practice; instead effective legal practice is a combination of the routine and the unexpected; the theoretical and the practical; and standard practice and improvisation. This means that effective lawyers have a range of skills both intellectual and practical and the personal abilities necessary to cope with the unexpected: ${ }^{11}$

b effective lawyers are able to learn for and by themselves from a wide variety of stimuli including lectures, texts and practical experiences with others and alone, and that in order to maximise on-going learning and professional development students should be encouraged to develop as autonomous selfinitiated learners not reliant on teachers to direct their learning;

c autonomous learners are characterised by an active, selfinitiated approach to learning and by a growing selfawareness about their personal best learning strategies; ${ }^{12}$

d autonomous learners are more likely to develop the ability to transfer knowledge and skills from one learned situation to another, and between different situations by the testing and development of personal problem-solving strategies; ${ }^{13}$

e the benefits of learning are maximised when they are supported by structured supervision and feedback and the opportunity for evaluation and reflection built into the 
learning environment; ${ }^{14}$ and

f development as an autonomous learner does not distinguish between intellectual and moral or personal development. ${ }^{15}$

The next step was to translate this "Credo" into practical working principles for course design by drawing out in more detail its pedagogical implications. The operational principles thus prompted a number of fundamental design decisions about the program. In order to encourage the development of autonomy in learning it would be necessary to present a varied diet of teaching and learning approaches to suit the range of different learning styles and preferences inevitably represented within the student body. Therefore the curriculum should be presented in a varied way using many different methods of teaching and learning and learners should be encouraged to develop personal learning strategies for both new and familiar tasks. Teaching methods would include Problem-Based Learning (the major vehicle for teaching substantive law on the program; see below), field trips, practice seminars dealing with legal skills, discussion groups, lectures and individual work on "in-trays". ${ }^{16}$

Maximising student participation and interactive learning on the program meant small group teaching. The program committed itself very early to the development of course material for use in small groups. Small groups maximise the opportunity for members to get to know each other relatively quickly and become comfortable; they reduce the logistical problems of co-operative team working which would often be required; and they make it feasible for the small group tutor to keep track of the contributions and progress of each individual member and give constant feedback and supervision. The program aims for very high levels of one-on-one and small group feedback. The nature of the feedback would however be different from many students' prior conceptions of teacher feedback. It would emphasise process as much as product and would present many and varied "right ways" to approach problem-solving rather than a unidimensional "right answer".

In order to encourage the development of autonomy and selfmanagement in learning the program adopted two major learning strategies both emphasising interactive methods of learning. The first is Problem-based Learning (PBL) in small groups. Central to the concept of PBL is the idea that students encounter the problem 
first and develop a knowledge base second. The knowledge base is developed through "need to know" problem-solving and research skills. The role of the tutor in PBL would not be to provide answers but rather to develop a supportive learning environment in which students were expected to carry out problem diagnosis and research for themselves with a minimum of tutor input and guidance. ${ }^{17}$

A second major learning strategy would be skills seminars concentrating on learning by demonstration, practice and feedback and would deal sequentially with legal skills including research methods, writing and drafting, interviewing, negotiation, advocacy and so on. These skills would be practised and refined again during the PBL exercises. These interactive methods of learning and teaching would be best suited to challenging students out of their learned passivity and would clearly articulate new expectations of participation and decision-making in the classroom.

Another major design decision which flowed from the operational principles was the creation of an appropriate physical and psycho-social working environment to support and facilitate the central learning tasks of the program. This meant providing a dedicated physical space which could be used by students on a full day office basis, with small group meeting rooms dedicated to each legal "firm". Computer facilities for the production of memoranda and documents were also provided along with a telephone to contact outside practitioners acting in an advisory capacity.

\section{ASSUMPTIONS AND WORKING HYPOTHESES}

The face-to-face student interviews which were to be conducted were focused by three working hypotheses developed by the researchers in advance of the interviews taking place. These working hypotheses comprised the basis of the researchers' original interest in the research project and were directly related to the evaluation of the success of the program design in achieving its intended learning outcomes.

The working hypotheses concentrated on examining student perceptions of any differences between the learning experience and expectations of this program and their earlier educational experiences; any subsequent changes in their approach to learning; and their perceptions of and reactions to the learning environment of the new program. 


\section{Hypothesis One}

That there are significant differences between the past and the present learning experiences of these students (these may include the difference between prescriptive expectations and demands in the past and more ambiguous and intangible expectations and demands in the present; a singular and unitary approach to learning in the past contrasted with a multi-dimensional and complex approach in the present experience). There are a range of possible student conceptions and perceptions of, and reactions to, these differences (these might include a readjustment of values about learning, difficulty relating past and present experiences, sometimes reversion to earlier learned security blankets, confusion about teacher expectations).

This first working hypothesis centred on what Biggs calls "presage" factors, ${ }^{18}$ that is factors which exist prior to learning. Our assumptions about presage factors were based on what we knew about the predominant forms of secondary education in Hong Kong which have tended historically to emphasise rote learning and memorisation and the heavy dependence of the learner upon the teacher. This appears to be the predominant model for the delivery of secondary education in Hong Kong but does not necessarily imply a learning stereotype for Hong Kong students as passive "surface" learners. On the contrary, Biggs's data ${ }^{19}$ suggest that Asian students widely adopt "deep" and "achieving" ${ }^{20}$ approaches to study. Nonetheless it is generally accepted that Hong Kong students display "almost unquestioning acceptance of the knowledge of the teacher or lecturer. ${ }^{21}$ By transferring much of the responsibility for learning from the teacher to the student, either individually or as a group, the new PCLL program would be quite unlike any earlier secondary school educational experience for this student group.

The same assumption was made about the students' previous experiences of tertiary education. Students on the PCLL come from three intake groups; City Polytechnic LLB graduates, graduates of the Extra-Mural LLB program run by Hong Kong University and LLB graduates from UK universities and polytechnics. The City Polytechnic LLB program is taught largely by large group lectures and smaller group tutorials. The assessments for this program take the form of closed-book examinations which for many students are 
commensurate with memorising large amounts of detail about decided legal cases and statutes. Students who came to the PCLL program from the Department of Extra-Mural Studies at Hong Kong University would have minimal experience of direct tutoring other than in large lecture classes where there was relatively little opportunity to critique, reflect on or evaluate information. The same assumption could be applied equally to graduates of the English institutions. Few of the English polytechnic law schools from which they had graduated have moved beyond the lecture/ tutorial style delivery in the traditional model of undergraduate legal education. ${ }^{22}$

We were aware then that the demands of the new PCLL would be unlike the demands these students were accustomed to in their previous educational experiences and that they would have a range of possible reactions to being asked to dance to a different tune. We realised that this might result in some "culture shock" for students entering the program. Clearly it was critical to student comfort that expectations were clarified as comprehensively and as early in the program as possible since these would be so far from the "norm" of earlier experience. It was hoped that the evaluation data would highlight areas where expectations were not being made sufficiently clear, in addition to providing a broad general picture of student responses to new expectations including the fears and anxieties generated as a consequence.

\section{Hypothesis Two}

The second working hypothesis was that differences between past and present learning experiences of the students would be reflected in individual student orientation and approach to study; for example, students would prepare differently for class, interact differently with their peers, approach their study tasks with different objectives, be more or less likely to study independently as a result, and/or in groups.

A large body of research and theoretical literature has developed on the theme of student learning styles and we were interested in exploring those explicit and some less overt changes in student work practices in response to the changed expectations being placed on them on the new program. ${ }^{23}$ For example, would the highly practical and applied nature of the program be reflected 
in changed patterns of study; would the emphasis on groupwork affect how students prepared for class; was there a danger that fear of failure on a new and unfamiliar learning program would produce instrumental strategies in response; and so on.

One of the interesting dimensions of exploring this hypothesis was that quantitative data already exists on the learning styles of the LLB graduate cohort on the PCLL program (approximately half of the total student group). The Study Process Questionnaire or SPQ, devised by Professor John Biggs, was administered to students on City Polytechnic's Bachelor of Laws program on four occasions over the three years that the first PCLL cohort was studying for the LLB. The SPQ asks respondents questions which relate to their learning style and study orientation. This data, although very different in nature to the qualitative and illuminative data gathered by this study, clearly suggested the potential for some later comparisons.

\section{Hypothesis Three}

The third and final hypothesis to be explored was that a changed approach to learning (above) would require a matching learning environment which could support the new kinds of learning experience and learning styles (where the learning environment includes physical space and facilities, student/teacher relationships, support mechanisms from both teachers and peers, and the general working atmosphere or "climate"), ${ }^{24}$ and that the creation of a suitable learning environment would better enable students to meet the program requirements.

The program had developed a tailor-made physical workplace environment for students to use as they went about their work on the program. This is described very briefly above. We hoped to discover how adequately this workplace environment supported students towards their achievement of program goals. We were also interested in student perceptions of the wider features of the learning climate (or "ambience, tone, atmosphere, ethos"). ${ }^{25}$ Research has suggested relationships ${ }^{26}$ between environment and approaches to study and the significance of student perceptions of and responses to environment. For example a number of studies have demonstrated that the kind of academic environment provided for students by the institution directly affects their approach to 
study or their meaning orientation. Our own hypothesis here was limited to discovering what we could about student perceptions of an appropriately supportive environment for the new program but future research and evaluation of the program could usefully examine this relationship.

\section{APPROACH AND METHODOLOGY}

The study was intended to be primarily descriptive in nature, that is its principal aim was to discover and describe a phenomenon (a set of meanings and understandings) rather than to explain something already identified and relate it to other phenomena. On a secondary level it was hoped that some clear indicators for program revision and modifications would emerge from the data (the evaluation function). Given this primary aim, a phenomenographic approach was adopted which was deliberately open in nature and intended to obtain student conceptions of their reality in the PCLL program, expressed in their own terms. While it was necessary to be open to a range of student perceptions and reactions, the working hypotheses encouraged respondents to express their understandings of the program, particularly in relation to the learning environment and changes in their approaches to study during their time in the program. To serve the evaluation purpose of the study information was also required on perceived positive and negative aspects of the program. All information was collected through semi-structured free response interviews.

A theoretical sampling approach to selecting respondents was adopted. Such an approach enables data collection to cease when no further (new and useful) information for the study is emerging from the data, in this case the interview texts. Notwithstanding this general approach, a high proportion of the students in the program were initially identified for interviewing. Respondents were randomly selected within major sub-groups represented in the program: males-females; under and over 25 years of age; graduates from the "parent" institution (City Polytechnic); graduates from Hong Kong University Extra-Mural Department who had obtained a law degree by part-time evening study — and graduates of other (largely English) institutions. Ultimately about $40 \%$ of the student cohort on the program were interviewed and the interviews recorded on audio-tape. 


\section{DATA ANALYSIS}

Both researchers listened many times to the audio-tape recordings of the face-to-face student interviews - a total of approximately twelve hours of discussion - and eventually began to derive categories of data reflecting students' conceptions of the program and their experience in it. These categories shed light on the original research hypotheses and provided further information for program evaluation. The analysis of data is reported below under these two headings, firstly research findings and secondly implications for program evaluation.

\section{RESEARCH FINDINGS}

\section{Hypothesis One}

Did students identify significant differences between their learning experience on this program and previous postsecondary experiences and how did they respond and adjust to this change?

Students were prompted to identify any perceived differences between their experiences of learning on the PCLL program and earlier educational experiences particularly at tertiary level. Almost all students clearly articulated considerable and significant differences of style, approach, and requirements and expectations. While a few concentrated only on differences of teaching method - contrasting lecture delivery of material with the Problem-Based Learning approach of the PCLL which required students to research and discover for themselves - most went further in drawing attention to consequential differences in teaching and learning patterns.

The major categories of perceived "differences" can be summarised under four headings.

Differences in ways of working co-operatively and as a team as compared with working individually and separately on earlier programs of study. Almost all the students interviewed gave this category the most emphasis in their description of "differences". It was clear from the remarks made that the team cooperation made necessary by the Problem-Based Learning method — which was organised in week-long legal problems or client files to which each "firm" or team of six to seven students was required to apply their collective efforts for a final presentation each Friday 
morning before a specialist legal practitioner — was a dramatic departure from the individualised study routines of previous tertiary experiences. Students recognised that the PBL method forced them into relationships of interdependence with their peers quite unlike their previous experiences which may have been limited to the formation of pre-examination study groups. The emphasis on group interaction produced both positive and negative reactions (see below).

As one student put it,

"A very great emphasis is put on group learning - for the past four years it has been lectures and seminars or tutorials, so we did a lot of learning from the lecturer, but now it's mainly doing our own research plus group discussions."

Another respondent made the point that, "the stress is now on group dynamics rather than having someone to teach us" and another commented, “... there is a lot of group work - before I learned alone.”

Differences in the role of the teacher/tutor. Many of the comments made about the role of the group in learning related to another of the major categories of perceived 'difference', that is, “There isn't much teaching in the real sense because the focus is on group learning ..." While this comment may not reflect the complexity of the role of the tutor in PBL to guide and facilitate rather than to direct, it represents a clear trend of perception amongst student respondents which singled out the changing role of the tutor as one of the characteristic differences in this program. Tutors were uniformly regarded as having abdicated their role as information providers and instead were recognised as providing signposts and overall process direction, for example on research and problem-solving techniques. Tutors were perceived not as subject experts - which certainly few of them were in relation to Hong Kong legal practice and none of them were in relation to all the subjects covered in PBL throughout the program - but as researchers with greater experience (even if not in the particular subject area under discussion), providing guidance on which processes to adopt and some general moral support. "Its more a way of teaching with the tutor around as someone you can ask when you are having difficulties ..." "Teaching? Learning is a more suitable word — the focus is not on the teacher teaching - 
here learning is by PBL with some guidance.” This accurate identification of the role of the tutor in PBL was not expressed without comment or judgement and the reactions of students to this new role for the classroom tutor varied quite widely (see below under Program Evaluation). None of the respondents saw the role played by the tutor as "accidental'; they were aware that it complemented the program goals and the expectations that they learn to work independently and on their own initiative and the reasons why this might be appropriate in a pre-professional context. As one student put it, “At the very beginning (of the program), I must admit that I was disappointed because there is a sudden change between the LLB and the PCLL teaching methods ... I realised (after a job interview) that the course is designed to let you know more about the real-life situation, gradually now I am getting used to the teaching method ...”

Differences in the form and substance of feedback. The next major category of perceived "difference" which is clearly related to both the categories discussed above pertains to the way in which students were given feedback on their work. Formative feedback on weekly PBL presentations and written products was left to the specialist legal practitioner who visited each group or firm on Fridays along with the group's own tutor. Feedback was given verbally rather than in writing on individual pieces of work. In form and in substance feedback was seen as being quite different from earlier experiences of grading or commentary on work products given on other post-secondary courses. Feedback on the PCLL program was often perceived as rather generalised in nature and not necessarily directed to whether the particular work product or products for that week were "good or of "pass" standard or got the "right" answer. Feedback was also often perceived as unstable, that is the quality and sometimes the content of the feedback given varied between the practitioners. On some occasions one group might discover when they compared notes afterwards with another group that they had received a different appraisal of a particular approach to the client problem, or a different interpretation of a relevant case or statute from different individual practitioners. They also remarked on the different abilities and styles of practitioners, most of whom had no teaching experience but all of whom would have had some role in the supervision of trainee solicitors at some 
point. In giving feedback, some were expansive, others were minimalist, some were harsh, others more forgiving of mistakes.

While it is not surprising, given the nature of legal practice itself, that feedback on practical legal exercises would rarely take the form of a "right” or "wrong” answer, many student respondents indicated that they found this form of feedback unsatisfactory. Comments on the nature of feedback were sometimes broadened into comments on the assessment system of the program generally. In particular, student anxiety was running high on the uncertain nature of the final examinations. ${ }^{27}$ This is dealt with further below under Program Evaluation.

More responsibility for autonomy and self-management in learning. Greater personal responsibility for self-directed learning was pointed out as a significant departure from earlier study experiences by a number of respondents. This is discussed in the following section, under approaches to study.

\section{Hypothesis Two}

Are differences between past and present learning experiences reflected in changes in individual student orientation and approaches to study?

Student respondents were prompted to consider whether they were aware of any changes in their individual orientation to study on this program. Most made reference to their earlier comments on group work and co-operation. Others described themselves as much more proximal task-orientated than on previous courses; the PCLL required them to complete a series of tasks week-by-week and they were increasingly focused on their next "product" and/or summative assessment task. ${ }^{28}$ Some, either in response to this prompt or later in the interview, described changes in the expectations placed on them to think and act autonomously which suggested some differences in study style and approach. For example,

"Unlike the LLB ... instead of receiving the data passively you have to do it for yourself so actually (knowledge) is generated from the students not from the teachers."

"Unlike the LLB course, the PCLL relies on self-initiative."

"Learning here depends on your own research; the teachers do not give the answers."

The following statement is likely to be indicative of movement from a "surface” towards a "deeper" approach to learning, 
"I like to ask questions and to think critically ... I like to learn from people other than reading the books ... learning from what the others say, of course with confirmation, I learn more and more deeply.”

In some cases however the heavy workload of course assessments combined with weekly learning targets for PBL seemed to indicate that task orientation could become dominated by largely instrumental motives which could reduce the benefits of other program goals for example group co-operation. As one respondent put it,

"Because of the coursework pressure ... it means to a certain extent that ... people are exam-orientated, they are thinking about the coursework all the time ... that will affect other kinds of learning."

Needless to say, despite some evidence from the interviews of a perception of the need for different approaches to study to complement the goals of the new program, the emphasis on selflearning was not uniformly popular with students who pointed to their consequent increased workload (see below under Program Evaluation).

\section{Program Evaluation}

The interviews revealed a considerable depth of student insight into the processes of learning on the program, in particular the overall program rationale of encouraging independent thought and action. In addition, all comments made by students included an element of positive and/or negative feedback on their levels of comfort and satisfaction with the program. A summary of the evaluative points made by students during their interviews appears below. Evaluative comments are arranged under each hypothesis, as above. Examination of hypothesis three was primarily evaluation rather than research-orientated, that is, it was limited to asking students to assess the adequacy and sufficiency of the learning environment provided for them and their level of comfort and satisfaction with it. Therefore discussion of student responses to this question has been confined to this final section on Program Evaluation.

Student feedback is recognised as one significant source of information on some important aspects of the program for evaluation purposes. Information provided by students, along with input from full-time teachers and the more than one hundred legal practitioners who had spent at least one morning with the students 
on the program during the 28 weeks of the program, have provided the course team with significant data which can assist in the formulation of proposals for program revision. Such proposals are currently being debated by the course team and some are outlined briefly below.

There are a number of intrinsic limitations on the use of data from these student interviews for evaluation purposes. The most obvious is that the data record student responses and reactions just three months into the program and do not reflect any increased familiarity with the program goals which one would expect after a longer period of time. Similarly it is often suggested that the "real" usefulness of an educational experience is apparent only once the student has an opportunity to fully reflect upon the experience in retrospect; and possibly to relate that experience to a new reality of learning tasks for example at work. Since the interviews were conducted relatively early in the course student responses were not affected by the onset of boredom or tedium which might be created by the repetition of teaching and learning methods over a 28 week period. However, a continued dialogue between tutors and students throughout the remainder of the program suggested to staff that there was in fact little marked change in student responses and reactions to the general questions posed. ${ }^{29}$

\section{Differences in the Learning Experience (Hypothesis One)}

There appeared to be little resistance to the central requirement of the PBL method that information generated within the small group should be shared. The only frequently voiced objection to this was related to the practicalities of dependency between group members - for example concern about the whole group suffering from one or two individuals failing to pull their weight. There seemed to be no general psychological tension related to difficulties with working with different personalities or reticence .about giving others the benefit of one's own research. Learning from peers, as well as and sometimes more than from tutors, was generally welcomed and approved by students. For example,

"(On my previous course) ... there was no chance to communicate with other students. When I took this course I thought that it was useful to have the chance to talk properly to other students and to learn from one another." 
Responses to the new increased significance of groupwork reflected differing experiences within particular small groups. By the time the interviews took place, students had spent 10 weeks working in one PBL small group and one larger group for practical skills training (for example in legal interviewing, research, drafting techniques and so on). They were now in a second 10 week period for which all groups had been reorganised. Some compared their levels of satisfaction now and earlier according to criteria based on group membership and consequent spirit of co-operation. Generally there was an acceptance of the principle that the groups should be reordered in this way on a regular basis to ensure that students were exposed to working with many different colleagues; as in real-life. However, there were a number of complaints that some group members who had outside commitments (for example family or work related) did not give enough time to informal group meetings and consultations and diminished the usefulness and productivity of the group as a learning vehicle.

This problem is often identified as an impediment to the use of groupwork learning strategies and the course team had listened to such reservations being expressed during the course development process. However it is important that it should not be overstated and the significance of the general willingness to engage in cooperative action overlooked. Many groups appeared, both from student comments and from the observations of their tutors, to work together well with a minimum of tutor intervention to ensure fair distribution of workloads. The course team is considering a number of ideas which might reduce the negative impact of group members who participate less fully than their peers might hope. A general question for the course team is how far they will manipulate the process of groupwork on projects to ensure equal participation from all members. Responsibility to ensure that the syllabus is covered and learned in sufficient detail has to be balanced against the importance the program rationale places on the development of autonomy in learning and encouraging students to take responsibility for their own learning; within the structure of Problem-Based Learning this inevitably includes facing some of the real-life difficulties of co-operation with others. Possible tutor responses to groups which are not sharing the workload evenly might include the tutor, rather than the students (usually the group 
chair for the week) allocating tasks; requiring all group members to do all the tasks rather than sharing them out; proposing that at the end of the week the final presentation should involve two groups who have been working on the same client file in a friendly competition to argue the most thorough and convincing case (an alternative version of this is to design exercises in which both sides of any action are prepared by different student groups).

While respondents generally demonstrated understanding of the different role of the tutor as facilitator and guide not all were comfortable with this. A number of students pointed out that few of the tutors had experience of legal practice in Hong Kong. Although they accepted that the tutor might not wish to provide them with the answers in order that their own research and problem-solving skills were developed, some were unhappy with the idea that the tutor would not be any more familiar with the law than they were themselves. This concern may in turn have been a reflection of the considerable tutor anxiety generated by their role. On the other hand, students characterised the tutor input which was forthcoming as helpful and useful.

This particular aspect of PBL - the role of the tutor as "nonexpert” - presents a number of psychological and practical difficulties for students and tutors. It can result in diminished student confidence in their tutors (expressed by a number of respondents) and can also affect tutor confidence in their ability to ensure that their students have met learning targets for the week's work. One student commented that

"PBL is more a way of teaching with the tutor around as someone you can ask if you are having difficulties. The problem is, we often don't see what the difficulties are we are facing ...”

This question has generated much discussion amongst the course team all year and a number of suggestions have been made to respond to concerns expressed by both students and tutors while maintaining -the commitment of the program to a PBL system in which tutors are not necessarily subject expert. ${ }^{30}$ Proposals include maximising teacher expertise by reducing the total number of problems and subject areas for which each tutor is responsible; the further and better use of 'resource persons' (outside legal practitioners who are subject experts) who can give help and advice to both tutor and students during the course of any one exercise; 
and clarifying student expectations about the role of the PBL tutor at an early stage in the program. In addition, it is expected that tutors will benefit from working with a particular problem a second or third time around and a tutor more confident with both their role and the problem will alleviate the concerns expressed this year by students.

Differences in the nature and style of feedback. It has already been noted above that the substance of feedback offered during the program was identified by many students as inconsistent, insufficiently related to work products and too general in substance. Many respondents called for more written feedback where possible - variously described by students as "guidelines", "sample answers" (already provided in this form for in-tray exercises) and "revision notes". The problem for the course team is to identify ways to ensure that adequate feedback is being given to students without being able to provide "right answers" which are not in the nature of either PBL or professional education. ${ }^{31}$ One proposal being considered by the course team is to formalise a role for the team subject specialist for each problem exercise (ie the exercise author) to be substantially relieved of other teaching responsibilities in order to provide systematic feedback on that exercise. This could be done in both small and larger groups and on an individual basis.

\section{Changes in Study Orientation (Hypothesis Two)}

Many students welcomed the changes in their own approaches to study of which they were becoming conscious and identified consequential benefits for them. For example,

"I think I learn more efficiently ... through the talking and the briefing from the others (group members)."

"In the past when I would do any paper I would ... simply change the sentence from the book. But at this moment I understand what it implies ... I feel more confident to write things down in my own language ... and I feel confident that my written and oral English has improved.”

Other respondents were less enthusiastic about the consequences of the PCLL learning strategies which placed a greater burden on them to take responsibility for their own learning. One described the process of approaching the tutor for help, and being told constantly to go away and do more research, as 
"frustrating”. Another student argued that it was "not sensible to make the student rely on their own research skills" and another commented that often “you don't know whether you go in the right direction or not, and then you find you are going in the wrong direction and ... you have already spent a lot of time ... a waste of time ..."

Students making these comments often related them directly to the sheer volume of workload they were expected to shoulder with minimal tutor input. This was clearly exacerbated by a heavy burden of regular courseworks and a feeling that the course proceeded at a relentless pace for its 28 weeks. The course team is exploring ways to reduce the summative coursework burden on students next year and making more of opportunities to give formative feedback on regular work products (see above). In addition, some students suggested that it might be helpful for summative assessments, which presently take place immediately after a particular segment of the course has been concluded, should occur a little later to give "time to consolidate what we have learned and also to learn about the other parts (of the exercise) ... done by other group members ...”. This is also being given active consideration.

\section{Satisfaction with Learning Environment (Hypothesis Three)}

During their interviews, students were prompted to consider the various elements of the learning environment, physical and psychosocial. Prompts given to respondents identified aspects such as physical space and resources including access to appropriate technologies; tutor support and assistance; and working atmosphere. Responses to this question were almost uniformly positive. Students were enthusiastic about the facilities provided for them - dedicated classroom space which they could access for 14 hours a day, their own computer facilities and photocopier, a specialist library resource centre - and it was clear from their responses that they saw the provision of these facilities as supporting their work on the program, both practically and psychologically (the program made "special” demands on them and hence "special" facilities were made available to them). Students spoke favourably of the atmosphere and ethos of the program, identifying specifically good relationships with staff and a feeling 
of team spirit and co-operation amongst students. Many spoke of a different kind of relationship formed with the tutor (see above) which was closer to a relationship of peers than previous experiences. Staff were praised for their friendliness and genuine interest in students. Negative comments related to the availability of some material in the Resource Centre (the program library), a matter which future planning must address.

\section{DISCUSSION AND CONCLUSIONS}

Most credible instructional design models stress the importance of assuring the adequacy of and consistency between the elements of instruction (objectives, teaching methods, learning experiences and assessments) for achieving overall instructional quality in relation to both processes and outcomes. Internationally, the trend in professional education (for example in medicine, social work, land surveying and law) has been towards a more pronounced adoption of this rationale in order to empower graduates to begin to practise effectively in their fields.

More specifically professional education programs have adopted two basic principles to guide the teaching-learning process. These principles are often described with reference to the terms "learning how to learn" and "learning by doing". The first of these principles relates to an intended outcome (objective) of a program, that is, that graduates should emerge having increased their capacity and ability to learn, not simply having learned set material during the program. There is wide agreement among professional education program developers that this global objective or goal is fundamentally important to the process of professional preparation given today's dynamic and fluid environment of professional knowledge and skills. The second principle, "learning by doing”, relates to the method of achieving (learning) objectives. Knowledge, skills and attitudes should be achieved by active participation in real-life or simulated tasks, experiences and problem-solving. In general, learning theory and research indicate that learning in this way provides an enhanced learning environment including; greater relevance of material, higher motivation and greater opportunity to meaningfully integrate skills and knowledge.

The program of professional legal education described in this 
paper has been designed according to the rationale and principles identified above. Specifically, its teaching and learning processes and the study environment have been designed to encourage students to develop as self-directed problem-solvers who are able to work co-operatively and effectively in teams. These design principles and the operational consequences which flowed from them suggested that many of the students in the program might experience a form of "culture shock", as their previous educational experiences would have been quite different. Such shock could inhibit the effectiveness of the program processes and outcomes. Both the "shock and the new demands of the program itself might also result in some identifiable changes in individual and collective student learning strategies.

This study aimed to discover early indications of the degree of fit between program intentions for student experience and the students' actual conceptions of the program. The results are useful for answering instructional innovation research questions and for providing input for program evaluation.

The data collected for the study indicated that the first cohort of PCLL students did experience a sense of "shock. This shock was caused by the demands which were being placed on them and the experiences they were having in the program. Both were radically different to their previous educational experiences. In summary, the major differences identified were:

1 The requirement of working co-operatively and productively at problem-solving tasks in small groups.

2 A changed tutor role, in which information channelling in a largely didactic manner is replaced by overall process direction and the provision of signposts in research, problemsolving, writing and performance activities.

3 The form and substance of feedback on learning and the products of learning have changed (related to two above).

4 The requirement that students develop autonomy in learning and self-management skills.

The second research question which the study addressed was concerned with early changes in students' approaches to study as a result of their responses to the program dynamics within the first three months. Students felt that they were learning in a quite different way through cooperative group work and that generally 
this was beneficial. Their input to and what they got from group work and other learning activities depended on their willingness and ability to be autonomous learners (for example carry out selfinitiated tasks, research, problem identification and so on). A significant number of students also felt that they were becoming more proximal task oriented in their approach to study; mainly due to the tight schedule of work and assessment tasks.

In relation to program evaluation a number of valuable findings emerged from the study. As indicated earlier, these need to be interpreted with some caution given that the students' experience of the program was relatively short at the time of the interview. Notwithstanding this limitation, students generally commended several instructional aspects of the program. In summary:

1 Inter-student communication is high and this enhances learning and their experience of learning.

2 Group problem-solving work is generally enjoyable and enables students to learn more and in different ways than with an individualised approach to study.

3 The program is highly practical.

4 The physical environment and resources are very good.

5 The psychosocial environment is good - in particular, the working atmosphere is good and teachers are friendly and helpful.

Students also identified several aspects of the program which they were concerned about or which they thought could be improved. Many respondents expressed the view that more and different feedback should be provided by tutors, particularly feedback which communicates to students the "closeness" of work or performance completed to the "ideal" (for example sample or model answers). Considerable student anxiety existed about the assessment workload, and in particular the suitability of the program content for preparing them for the final examinations. The context in which these final examinations take place and their relationship to the remainder of the instructional design process have been discussed briefly above. Another commonly expressed concern related to the levels of tutor expertise in areas of law, compared to their expertise as instructional facilitators.

This study has concentrated on students' conceptions of an instructional design and its operational processes. The data it has 
produced sheds light on the "fit" between instructional design and student learning on the program. Notwithstanding its limitations, it indicates that several of the instructional design features of this new program are having their intended positive effects on student learning. It also identifies some areas where the "fit" is less complete than course planners intended and provides valuable information to the course team on which to base program modifications.

* Formerly City Polytechnic of Hong Kong.

** Australian National University.

(c) 1993. (1993) 4 Legal Educ Rev 63.

1 F Marton, Phenomenography - A Research Approach to Investigating Different Understandings of Reality (1986) $21 \mathrm{~J}$ Thought 28.

2 Marton, supra note 1, at 31.

3 See generally WJ Popham, Educational Evaluation (Englewood Cliffs: Prentice Hall, 1980).

4 The Basic Law, enshrined in the Joint Sino-British Declaration of 1987, guarantees the continuation of the common law system for 50 years beyond 1997. The effectiveness of this guarantee post-1997 has yet to be tested.

See for example, the report of the Marre Committee. Report of the Committee on the Future of the Legal Profession (Marre Report) (London: Law Society of England and Wales, Bar of England and Wales, 1988). The Marre Report built on many earlier comments and proposals such as Lord Chancellors Committee on Legal Education (the Ormrod Committee) (London: HMSO, 1971) Cmnd 4595; Report to the Social Sciences and Humanities Research Council of Canada by the Consultative Group on Research and Education in Law: Law and Learning (Arthurs Report) (Toronto: Social Sciences and Humanities Research Council of Canada, 1983); Commonwealth Tertiary Education Commission, Australian Law Schools: A Discipline Assessment for the Commonwealth Tertiary Education Commission (Pearce Report) (Canberra: AGPS, 1987); American Bar Association Task Force on Law Competency, Report on Law Competency: the Role of Law School (Crampton Report) (Chicago: ABA, 1979); American Bar Association Task Force on Law Schools, Law Schools and the Profession: Narrowing the Gap (McCrate Report) (Chicago: ABA, 1991).

6 See for example the work of Donald Schon and Chris Argyris. DA Schon, Reflective Practitioner (New York, Basic Books 1983); Educating the Reflective Practitioner (San Francisco: Jossey Bass, 1985); C Argyris, Theory into Practice: Increasing Professional Effectiveness (San Francisco: Jossey Bass, 1974).

7 See generally $\mathrm{T}$ Andre, Problem-Solving and Education, in M Moon \& $\mathrm{P}$ Murphy eds, Developments in Learning and Assessment (London: Hodder \& Stoughton, 1989). For a problem-solving perspective on legal education, see for example, S Nathanson, Problem-Solving in Professional Legal Education, in $\mathrm{R}$ Wacks ed, The Future of Legal Education and the Legal Profession in Hong Kong (Hong Kong: Hong Kong University Press 1989).

8 See for example P Wesley-Smith, Neither a Trade nor a Solemn Jugglery: Law as Liberal Education, in R Wacks ed, The Future of Legal Education and the Legal Profession in Hong Kong (Hong Kong: Hong Kong University Press 1989).

9 For a full statement see J Macfarlane et al, Designing the Legal Practice Course: the Hong Kong Plan (1992) 26 L Teach 84. 
The design model deliberately eschewed an objectives-led approach preferring a combination of a process and an objectives-led approach. As John Dewey put it "the process and the goal of education are one and the same thing." J Dewey, My Pedagogic Creed Explained, in J McDermott ed, The Philosophy of John Davey vol 2 (Chicago: University of Chicago Press, 1981) 450.

See Schon, supra note 6, and Argyris, supra note 6.

12 For one set of paradigms of different personal learning styles, see D Kolb, Experiential Learning: Experience as the Source of Learning and Development (Englewood Cliffs: Prentice Hall, 1984).

13 For example in the use of Problem-Based Learning methods (PBL) see $\mathrm{H}$ Barrows \& R Tamblyn, Problem-Based Learning: An Approach to Medical Education (New York: Springer, 1980); GR Norman, Problem- Solving and Problem-Based Learning (1988) 22 Med Educ 279.

14 See for example K Kreiling, Clinical Education and Lawyer Competency: the Process of Learning to Learn through Properly Structured Supervision (1981) 40 Md LR 284.

15 See for example the work on the academic and moral development of college students by William Perry. W Perry, Forms of Intellectual and Ethical Development in the College Years (New York: Holt Rinehart \& Winston, 1970).

16 An "in-tray" is an individual student exercise simulating a typical task left in a trainee's in-tray for them to complete and usually requires responding to an internal memorandum from a senior or the completion of documentation for a client file.

17 For a discussion of the role of the tutor in Problem-Based Learning see for example VR Neufeld \& HS Barrows, The McMaster Philosophy: An Approach to Medical Education (1974) $49 \mathrm{~J}$ Med Educ 1040, at 1047.

18 J Biggs, Teaching for Better Learning (1990-91) 2 Legal Educ Rev 133, at 136.

19 J Biggs, Asian Students' Approaches to Learning: Implications for Teaching Overseas Students, in M Kratzing ed, Proceedings of the 8th Australasian Learning and Language Conference 1 (Queensland: Queensland University of Technology, 1990).

20 For an explanation of the meaning of these terms which are used widely in educational research and evaluation, see $\mathrm{N}$ Entwistle \& $\mathrm{P}$ Ramsden, Understanding Student Learning (New York: C Helm Nicols, 1982). See also Biggs, supra note 18.

21 D Murphy, Offshore Education: A Hong Kong Perspective (1987) 30 Aust $U$ $\operatorname{Rev} 30$, at 43.

22 These institutions are still dominated by the traditional lecture/ tutorial method of information transmission. See J Bailey, Law Teaching Methodologies(PhD thesis, 1985).

23 See for example NJ Entwistle, M Hanley \& G Ratcliffe, Approaches to Learning and Levels of Understanding (1979) Brit Educ Res J 99; NJ Entwistle, JB Thompson \& JD Wilson, Motivation and Study Habits (1974) Higher Educ 379.

24 One instrument widely used and validated to explore classroom climate and psycho-social environment is the CUCEI. It gathers data in relation to seven critical determinants of classroom environment and climate ie personalisation, involvement, task orientation, student cohesiveness, satisfaction, innovation and individualisation. See B Fraser \& D Treagust, Validity and Use of an Instrument for Assessing Classroom Psycho-social Environment in Higher Education (1986) 15 Higher Educ 37, at 42.

25 See B Fraser, Twenty Years of Classroom Climate Work: Progress and Prospects (1989) 21 J Curriculum Stud 207.

26 See NJ Entwistle \& H Tait, Approaches to Learning, Evaluations of Teaching and Preferences for Contrasting Academic Environments (1990) 19 Higher 
Educ 169.

27 One extraordinary aspect of the initiation of the new PCLL was that its recognition by the local legal profession was subject to an agreement made between the Polytechnic, the University of Hong Kong and the two branches of the profession in March 1991. This agreement states that the final examinations (which account for $30 \%$ of students' final marks) must follow a form consistent with the PCLL program offered by the University of Hong Kong and be approved by the legal profession (through an appointed committee). This constraint on the complete integration of the final element of the assessment process into the remainder of the instructional design process has caused many as yet unresolved difficulties in adequately matching the requirements of these examination papers to program objectives and the teaching and learning processes.

28 In its first year the program required students to take and pass a total of twelve in-course summative assessments, approximately one every 3 to 4 weeks.

29 In addition to regular informal discussion and feedback (enhanced by a staffstudent ratio of approximately 1:7), 30 minutes of the small group "Homebase" sessions (which met two out of every three weeks) were devoted to a student-led agenda in which students could (and did) take the opportunity to comment a any aspect of the program, how they were dealing with its demands, specific requests for extra support facilities and so on. Homebase tutors channelled comments back to the full staff group for discussion where appropriate.

30 It is characteristic of Problem-Based Learning that non-expert tutors (although experienced professionals within the field) are used as facilitators. It is considered that over-familiarity with the particular subject area might tempt the tutor to intervene too early and too directly in the process. Furthermore the logistics of small group size used for PBL require that staff tutor in areas beyond their subject specialism.

31 See Schon, Reflective Practitioner, supra note 6, at 37-49 for a rejection of the idea of "technical rationality" (leading to “a right answer”) in professional problem-solving and decision-making. The program had adopted this position in formulating its original design principles. 